\title{
The Turbulence Intensity Effect on the Flow Characteristics and Aerodynamics of a Circular Cylinder
}

\author{
İlyas KARASU ${ }^{1}$ ORCID $0000-0003-3118-6236$ \\ Sergen TÜMSE ${ }^{* 2}$ ORCID $0000-0003-4764-747 X$
}

${ }^{1}$ Adana Alparslan Türkeş Science and Technology University, Department of Aerospace Engineering, Adana

${ }^{2}$ Çukurova University, Faculty of Engineering, Department of Mechanical Engineering, Adana

Geliş tarihi: 28.07.2021 Kabul tarihi: 10.12.2021

Atıf şekli/ How to cite: KARASU, I., TÜMSE, S., (2021). The Turbulence Intensity Effect on the Flow Characteristics and Aerodynamics of a Circular Cylinder. Çukurova Üniversitesi, Mühendislik Fakültesi Dergisi, 36(4), 901-912.

\begin{abstract}
In this investigation, a numerical study about the turbulence intensity effect on the time-dependent flow structure around a circular cylinder employing k- $\omega$ based Detached Eddy Simulation (DES) turbulence model was performed at sub-critical Reynolds number of $R e=5 \times 10^{3}$. According to the numerical analyses, the length of recirculation region reduces as the level of turbulence intensity augments. While the normalized length of recirculation region after the cylinder, $L_{S} / D$ is measured as 1.225 at turbulence intensity of $T u=0.8 \%$, it reduces to the value of $L_{s} / D=1.0822$ at turbulence intensity of $T u=7 \%$. Furthermore, the location of peak negative pressure coefficient moves in downstream direction by increasing turbulence intensity. The drag coefficient, $C_{D}$ was observed to increase when turbulence intensity increases from $T u=0.8 \%$ to $7 \%$ and $12 \%$. Thus, it was concluded that the level of turbulence intensity is effective on changing the flow characteristics and aerodynamics of a circular cylinder.
\end{abstract}

Keywords: Bluff body, Subcritical Reynolds number, Turbulence intensity, Turbulence model, Unsteady flow

\section{Türbülans Şiddetinin Dairesel Bir Silindir Üzerinde Oluşan Akış Yapısına ve Aerodinamiğine Etkisi}

\section{$\ddot{\mathbf{O} z}$}

$\mathrm{Bu}$ araştırmada, kritik altı Reynolds sayısının, $R e=5 \times 10^{3}$ olduğu durumda $\mathrm{k}-\omega$ tabanlı DES türbülans modeli kullanılarak türbülans şiddetinin dairesel bir silindir etrafındaki zamana bağlı akış yapısı üzerindeki etkisi hakkında sayısal bir çalışma yapılmıştır. Sayısal analizlere göre, türbülans şiddeti arttıkça ayrılmış akış bölgesinin uzunluğu azalmaktadır. Silindirin arka bölgesinde oluşan ayrılmış akış

\footnotetext{
*Corresponding author (Sorumlu yazar): Sergen TÜMSE, stumse@cu.edu.tr
} 
bölgesinin uzunluğu, $L_{s}$ silindirin çapı, $D$ ile boyutsuzlaştırılmış ve bu değer, $L_{s} / D$ türbülans şiddetinin $T u=\% 0,8$ olduğu durumda $L_{s} / D=1,225$ olarak ölçülürken, türbülans şiddetinin $T u=\% 7$ olduğu durumda $L_{s} \delta D=1,0822$ değerine azalmıştır. Ayrıca silindir yüzeyinde mutlak negatif basınç katsayısının maksimum olduğu nokta, türbülans şiddeti arttıkça silindir arka bölgesinde oluşan durma noktasına yaklaşmıştır. Türbülans şiddetinin, $T u=\% 0,8$ olduğunu durumdan $T u=\% 7$ ve $\% 12$ olduğu durumlara arttırıldığında, sürükleme katsayısının, $C_{D}$ arttığı gözlemlenmiştir. Buradan türbülans şiddeti seviyesinin dairesel bir silindir etrafında oluşan akış karakteristiği ve aerodinamiği üzerinde etkili olduğu sonucuna varılmıştır.

Anahtar Kelimeler: Küt cisim, Kritik altı Reynolds sayısı, Türbülans şiddeti, Türbülans modeli, Kararsız akış

\section{INTRODUCTION}

The cylinder is the most commonly used geometry for the investigations of bluff body aerodynamics and the flow around a cylinder is encountered in many engineering applications [1]. The flow around the cylinder has been experimentally studied by many researchers and its physics has been revealed for Reynolds number within various ranges. When the instantaneous flow pattern around the cylinder is examined, it has been shown that the vortex shedding and fluctuating flow structure takes place after the fluid flow separates from the cylinder surface. The periodic shed of vortices and high-level fluctuations in the wake region may cause problems such as noise and vibration $[2,3]$. The time-averaged flow structure around the cylinder are composed of two counter rotating vortices in the wake flow region and a separation point. As stated by Najafi et al. [4] the drag coefficient, $C_{D}$ and length of the wake region differ in the literature due to the factors such as blockage ratio, turbulence intensity of the freestream flow, and surface roughness for the same Reynolds number. In addition to the experimental studies, numerical studies investigating flow structure the flow structure around bluff bodies has been increasing. Mannini et al. [5] compared the flow structure around a rectangular cross section by using numerical method of Unsteady Reynolds Averaged Navier-Stokes (URANS) and Detached Eddy Simulation (DES) turbulence models at Reynolds number, $R e=21600$. According to the results, DES always provides results closer to the experimental studies and while URANS gave a partially good results when the edge ratios of rectangle were $5: 1$, neither $2 \mathrm{D}$ nor $3 \mathrm{D}$ URANS simulations could give as accurate results as $3 \mathrm{D}$
DES at edge ratios of rectangle, 1:5. You and Kwon [6] investigated the flow structure around a circular cylinder by using Spalarat-Almaras (S-A) model, Spalarat-Almaras (S-A) based DES model and k- $\omega$ SST based Scale-Adaptive Simulation (SAS) model at Reynolds number, $R e=3 \times 10^{6}$. They revealed that when the destruction term was activated in the DES turbulence model, and the specific dissipation rate was increased in the SAS model, the more accurate results are obtained compared to the RANS model simulations. Uzun and Hussaini [7] carried out Delayed Detached Eddy Simulation (DDES) to investigate the flow behavior around tandem cylinders. In this study, 133 million grid points are performed to assess the sensitivity of the estimations to grid resolution. They stated that DDES results are rather in good agreement with experimental ones. The timeaveraged streamline pattern from DDES simulation supply a proof that the separation point of the boundary layer is similar to the one that acquired with PIV experiments. Travin et al. [8] studied DES past a circular cylinder with laminar separation at $\operatorname{Re}=50 \times 10^{3}$ and with turbulent separation at $R e=140 \times 10^{3}$ and $3 \times 10^{6}$. According to them, the results are more accurate with DES turbulence model compared to the URANS turbulence model for laminar separation cases. But the accuracy level of URANS and LES is very close to the each other for turbulent separation case. The Zhao et al. [9] performed a numerical investigation about the flow behavior around a circular cylinder with $k-\omega$ shear stress transport (SST) based DES turbulence model to investigate massively separated flow. According to the authors, most mean values are not delicate to the resolution and length the spanwise. A difference was observed between the severity of estimated 
pressure distributions throughout the surface of the cylinder acquired in this study and some experimental studies. Zhao et al. [10] comprehensively studied the flow structure past a circular cylinder with DES turbulence model at Reynolds number, $R e=3900$. In this study the impacts of the spanwise lengths, grid resolutions and numerical schemes are discussed. They revealed that very coarse and fine grids weaken the performance of DES model. According to them, for the steady flow pattern, while second order schemes are sufficiently effective, the higher-order model are necessitated for the time-independent flow characteristics. Karasu [11], used different models of turbulence to determine the unsteady flow structure around the cylinder at $R e=5000$. He showed that LES and DES models gave very close results in experimental study in all parameters examined comparing with URANS models. Norberg and Sunden [12] experimentally investigated the influence of the turbulence intensity and Reynolds number on the flow structure past a circular cylinder at Reynolds number within the range of $2 \times 10^{4}$ and $3 \times 10^{5}$ and turbulence intensities in free-stream flow as $0.1 \%$ and $0.4 \%$. They pointed out that pressure forces increase when the turbulence intensity gets higher for Reynolds number smaller than, $10^{5}$, while reverse effect was detected for higher Reynolds numbers. According to authors, the impacts of Reynolds number and turbulence intensity on the root mean square of pressure coefficient at subcritical regime are very significant, but this effect attenuates by increasing Reynolds numbers. It was noticed that the turbulence intensity does not depend on the blockage ratio. Furthermore, when the turbulence intensity increases from $0.1 \%$ to $0.4 \%$, the Strouhal number was detected to reduce for Reynolds number smaller than $10^{5}$ whereas the Strouhal number increases with increasing turbulence intensity at greater Reynolds numbers. The flow transition regime moves upstream of the cylinder by increase in Reynolds number and/or turbulence intensity [13-14]. In the investigation of Ahn et al. [15], the timeindependent heat transfer characteristics of a circular cylinder has been comprehensively studied by numerical model as a function of turbulence intensity of free-stream flow and Reynolds number
According to authors, the frequencies of fluctuations were observed to almost uniform over the whole periphery of cylinder surface. As estimated, the value of heat transfer coefficient augments when the turbulence intensity of freestream flow gets higher. The authors pointed out that the magnitude of the Strouhal number is independent of the value of the turbulence intensity and it only slightly changes with Reynolds number. Smith and Kuethe [16] carried out flow analysis at the cylinder's stagnation point in cross flow. They revealed that there is a direct proportion eddy viscosity and turbulence intensity. Sunden [17] analytically studied the influence of turbulence intensity and length scale of turbulence on the boundary layer model to investigate turbulence effects in steady flow with a main emphasis on stagnation point. According to them, for a given scale, the Nusselt number was detected to go up with increase in the value of TuRe ${ }^{1 / 2}$

The aim of the present study is to numerically study the effect of a turbulence intensity of freestream flow on the flow characteristics around a circular cylinder such as drag coefficient, $C_{D}$, pressure distribution, time-averaged streamline and velocity patterns at Reynolds number, $R e=5 \times 10^{3}$.

\section{MATERIAL VE METHOD}

\subsection{Flow Configuration and Numerical Setup}

The description of the essential geometrical and flow parameters for the flow on a circular cylinder is demonstrated in Figure 1 where $0^{\circ}$ and $180^{\circ}$ denotes front and rear stagnation points, respectively. The flow shown here is from left to the right and the angle, $\theta$ is measured in downstream direction, from front stagnation point to rear stagnation point. Here $F$ shows the location of foci and it is the center of vortices. $S$ is the saddle point that displays the position in the flow region where the velocity of fluid flow is zero. $S$ also represents the reattachment point. $L_{s}$ is the separation length where the distance between rear stagnation point and saddle point, $S$. The separation length, $L_{s}$ is normalized with the cylinder diameter, $D$. 


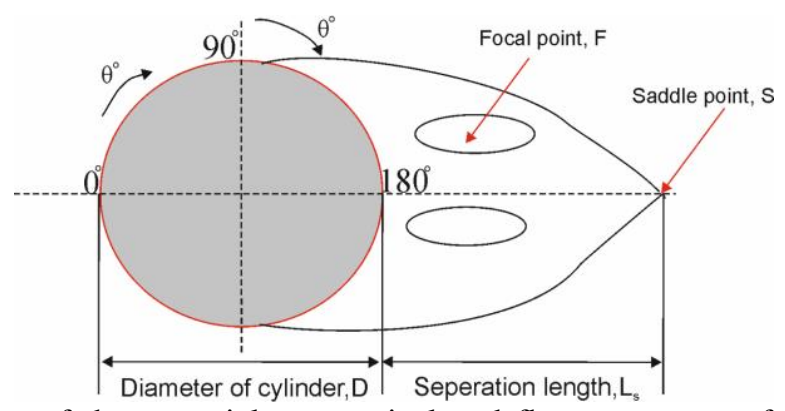

Figure 1. The description of the essential geometrical and flow parameters for the flow on a circular cylinder

In all numerical simulations, $\mathrm{O}$ type grid structure created using GAMBIT software was utilized. The sizes of the flow field were demonstrated in Figure 2 in terms of the cylinder diameter, $D$ (not to scale). The diameter of the outer cylinder forming the entire flow field is $50 \mathrm{D}$, and the thickness of the flow field is given as $\Pi D$ along $\mathrm{z}$-axis. Figure 3 $a$ and $b$ demonstrates the general view of the mesh structure and mesh structure around the cylinder, respectively. The diameter of the cylinder is divided into 200 parts and the y-axis in the region outside of the cylinder is divided into 150 parts, the mesh around the cylinder has become denser, it has been opened regularly towards the inlet and outlet. The thickness of the $\Pi D$ given to the cylinder was divided into 48 equal parts. As stated by Sidebottom et al. [18], the thickness and number of nodes in the z-axis is sufficient to model the flow.

There are 1479800 nodes in the mesh structure. Surface velocity in the first half of the outer cylinder inlet, surface pressure outlet on the other half and both surfaces of the outer cylinder was chosen as symmetry. In order to show mesh independency, the numerical simulations have been made with four different mesh structures which each one includes different number of nodes. Figure 4 shows the drag coefficient, $C_{D}$ values with four different mesh structures. As seen in Figure 4, the difference between drag coefficient, $C_{D}$ values are very low for four different generated mesh structures. After approximately $1.2 \times 10^{6}$ number of nodes, the drag coefficient, $C_{D}$ values does not almost change, so that reason the mesh structure with 1479800 nodes is chosen for the numerical simulation of 3D flow past a circular cylinder.

The numerical solutions were carried out with a computer with two E3-1240 v5 processors and 32 GB RAM using ANSYS FLUENT 18.1 software with finite volume method. During the simulations with DES model, for pressure and velocity coupling the PISO (Pressure-Implicit with Splitting of Operators), for pressure discretization the PRESTO algorithm has been utilized. Limited central differences are used for pressure discretization and second order formulation is used for time-dependent solutions. The minimum orthogonal quality of the generated mesh structure is 0.995 .

All solutions were carried out at Reynolds number, $R e=5 \times 10^{3}$. The time step size, $\Delta t$ was adjusted as $\Delta t=5 \times 10^{-5} \mathrm{~s}$ and thus CFL number was kept below one. In this study, same method was applied with Karasu [11]. Flow characteristics and force coefficients on the cylinder depend on many parameters such as Reynolds number, blockage ratio, turbulence intensity of free-stream flow and surface roughness at the cylinder. Therefore, the drag coefficient obtained in this study are consistent with the experimental studies of Najafi et al. [4] and Durhasan et al. [19] performed at similar Reynolds number and turbulence intensities. In this study, the flow characteristics was obtained with PIV method in water channel, and the drag forces was measured in the wind tunnel. Reynolds number, drag coefficient and Strouhal number was calculated based on the Equations of 1, 2 and 3 respectively. 


$$
\begin{aligned}
& \mathrm{Re}=\frac{\rho \mathrm{UD}}{\mu} \\
& \mathrm{C}_{\mathrm{D}}=\frac{\mathrm{F}_{\mathrm{D}}}{0.5 \rho \mathrm{U}^{2} \mathrm{~A}} \\
& \mathrm{~S}_{\mathrm{t}}=\frac{\mathrm{fD}}{\mathrm{U}}
\end{aligned}
$$

(1) In these equations, $\rho$ is the density of the fluid, $U$ is the free-stream flow velocity, $D$ is the diameter of the cylinder, $\mu$ is the dynamic viscosity of the (2) fluid, $F_{D}$ is the drag force, $A$ is the frontal area of the cylinder which is the multiplication of length, (3) $L$ and diameter of the cylinder, $D, A=L D, f$ is the (3) dominant frequency acquired from lift coefficient.

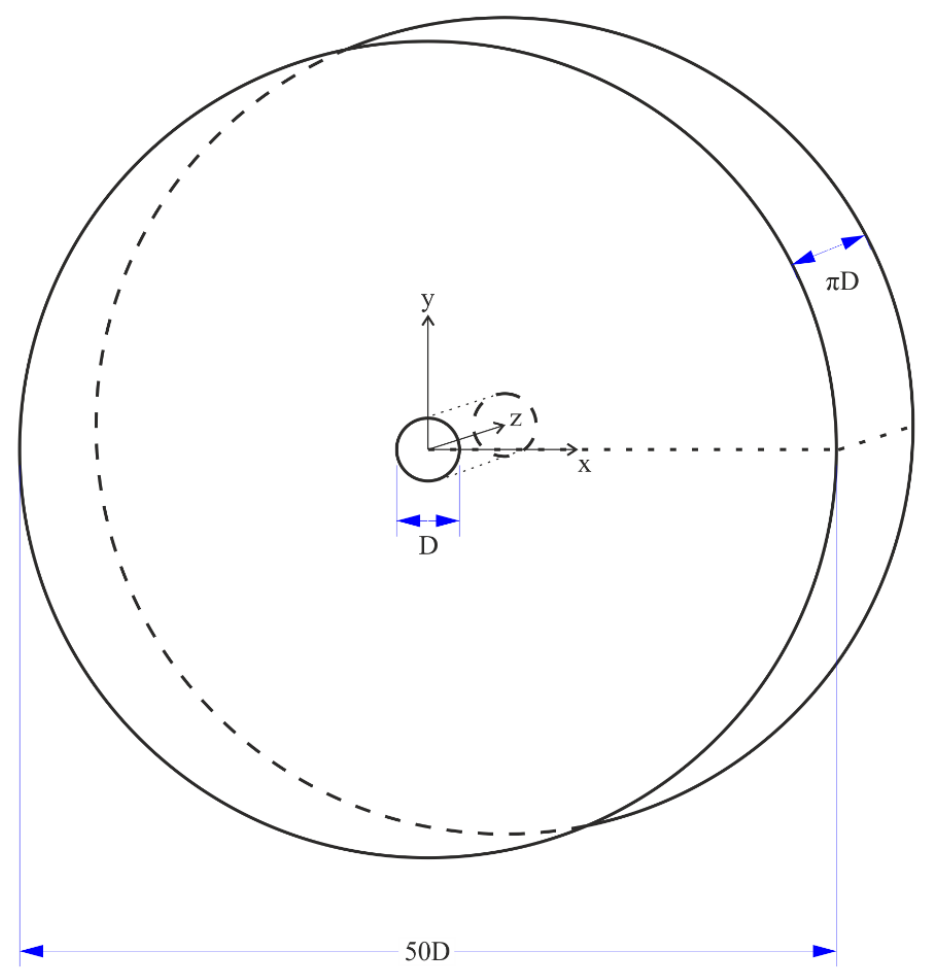

Figure 2. The sizes of flow field in terms of the cylinder diameter, $D$

\subsection{Detached Eddy Simulation Turbulence Modeling \\ (DES) \\ $\mathrm{F}_{1}=\tanh \left(\arg _{1}^{4}\right), \arg _{1}=\min \left[\max \left(\frac{\sqrt{\mathrm{k}}}{\beta^{*} \omega \mathrm{y}}, \frac{500 \mathrm{v}}{\mathrm{y}^{2} \omega}\right), \frac{4 \alpha_{\omega 2} \mathrm{k}}{\mathrm{CD}^{*}{ }_{\mathrm{k} \omega} \mathrm{y}^{2}}\right]$}

The k- $\omega$ equations are given in Equations 4-11;

$\frac{\partial \mathrm{k}}{\partial \mathrm{t}}+\frac{\partial\left(\mathrm{u}_{\mathrm{j}} \mathrm{k}\right)}{\partial \mathrm{x}_{\mathrm{j}}}=\mathrm{G}^{\sim}-\beta^{*} \mathrm{k} \omega+\frac{\partial}{\partial \mathrm{x}_{\mathrm{j}}}\left[\left(\mathrm{v}+\alpha_{\mathrm{k}} \mathrm{v}_{\mathrm{t}}\right) \frac{\partial \mathrm{k}}{\partial \mathrm{x}_{\mathrm{j}}}\right]$

$\frac{\partial \omega}{\partial t}+\frac{\partial\left(u_{j} \omega\right)}{\partial x_{j}}=Y S^{2}-\beta \omega^{2}+\frac{\partial}{\partial x_{j}}\left[\left(v+\alpha_{\omega} v_{t}\right) \frac{\partial \omega}{\partial x_{j}}\right]+\left(1-F_{1}\right) C D_{k \omega}$

in which, $\mathrm{G}^{\sim}=\min \left(\mathrm{G}, \mathrm{c}_{1} \beta^{*} \mathrm{k} \omega\right)$ and $\mathrm{G}=\mathrm{v}_{\mathrm{t}} \mathrm{S}^{2} . F_{l}$ is a blending that is described as in which $\quad \mathrm{CD}_{\mathrm{k} \omega}^{*}=\max \left(\mathrm{CD}_{\mathrm{k} \omega}, 10^{-10}\right)$ and $\mathrm{CD}_{\mathrm{k} \omega}=2 \alpha_{\omega 2} \frac{1}{\omega} \frac{\partial \mathrm{k}}{\partial \mathrm{x}_{\mathrm{j}}} \frac{\partial \omega}{\partial \mathrm{x}_{\mathrm{j}}}$. The whole constant in transports equations are acquired by blending function;

$\varnothing=\mathrm{F}_{1} \varnothing_{1}+\left(1-\mathrm{F}_{1}\right) \varnothing_{2}$

where $\varnothing$ presents $\alpha, \beta$ and $\gamma$ in the $\mathrm{k}$ - and $\omega$ equations. The eddy viscosity is described as 
$\mathrm{v}_{\mathrm{t}=} \frac{\mathrm{a}_{1} \mathrm{k}}{\max \left(\mathrm{a}_{1} \omega, \mathrm{b}_{1} \mathrm{SF}_{2}\right)}$

in which $\mathrm{S}$ is the strain rate described as $\mathrm{S}=\sqrt{2 \mathrm{~S}_{\mathrm{ij}} \mathrm{S}_{\mathrm{ij}}}$ and $\mathrm{S}_{\mathrm{ij}}=\frac{1}{2}\left(\frac{\partial \mathrm{u}_{\mathrm{i}}}{\partial \mathrm{x}_{\mathrm{j}}}+\frac{\partial \mathrm{u}_{\mathrm{j}}}{\partial \mathrm{x}_{\mathrm{i}}}\right)$ and $F_{2}$ is the other blending function determined as

$\mathrm{F}_{2}=\tanh \left(\arg _{2}{ }^{2}\right), \arg _{2}=\max \left(2 \frac{\sqrt{\mathrm{k}}}{\beta^{*} \omega \mathrm{y}}, \frac{500 \mathrm{v}}{\mathrm{y}^{2} \omega}\right)$

The whole constants utilized in this study are the identical with the investigation of Menter et al. [20].

\subsubsection{DES Modification}

As stated by Menter et al. [20], the k-equation is altered by adding a production coefficient $F_{D E S}$ to the dissipation term

$\frac{\partial \mathrm{k}}{\partial \mathrm{t}}+\frac{\partial\left(\mathrm{u}_{\mathrm{j}} \mathrm{k}\right)}{\partial \mathrm{x}_{\mathrm{j}}}=\mathrm{G}^{\sim}-\beta^{*} \mathrm{k} \omega \mathrm{F}_{\mathrm{DES}}+\frac{\partial}{\partial \mathrm{x}_{\mathrm{j}}}\left[\left(\mathrm{v}+\alpha_{\mathrm{k}} \mathrm{v}_{\mathrm{t}}\right) \frac{\partial \mathrm{k}}{\partial \mathrm{x}_{\mathrm{j}}}\right]$

where $F_{D E S}$ is described as

$\mathrm{F}_{\mathrm{DES}}=\max \left(\frac{\mathrm{L}_{\mathrm{t}}}{\mathrm{C}_{\mathrm{DES} \Delta}}\left(1-\mathrm{F}_{\mathrm{S}}\right), 1\right)$

in which $L_{t}$ is the calculated turbulent length scale, $\mathrm{L}_{\mathrm{t}}=\sqrt{\mathrm{k}} /\left(\beta^{*} \omega\right)$ and $\Delta$ is the grid size, $\Delta=\sqrt[3]{\Delta \mathrm{x} \Delta \mathrm{y} \Delta \mathrm{z}}$ is the, $C_{D E S}$ is the DES constant which is equal to 0.61 herein. $F_{S}$ can be $F_{1}$ or $F_{2}, F_{2}$ is utilized in this investigation.

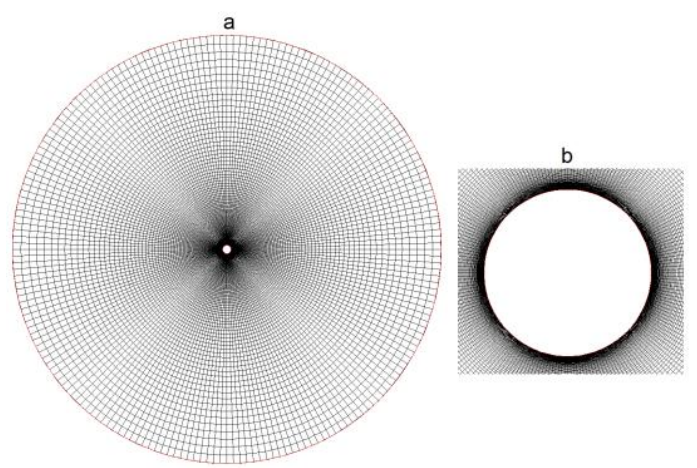

Figure 3. a) The general view of the mesh structure b) Mesh structure around the cylinder

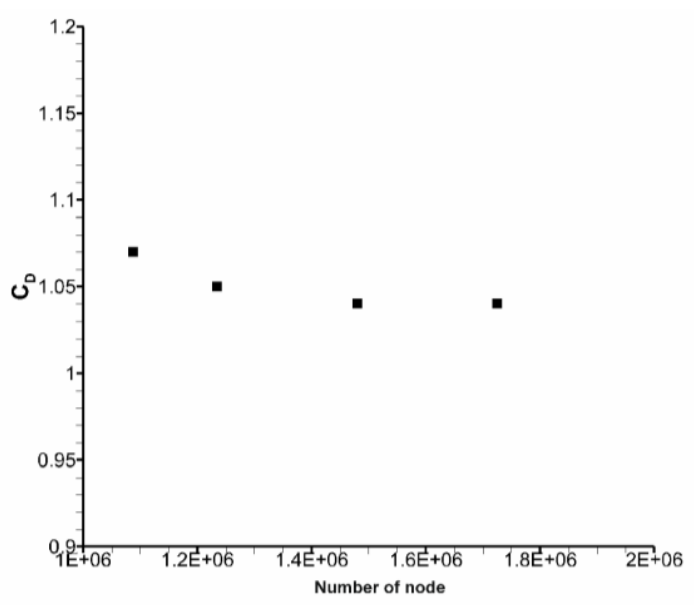

Figure 4. Drag coefficient values, $C_{D}$ for four different mesh structures with different number of nodes

\section{RESULTS AND DISCUSSION}

Figure 5 demonstrates the effect of turbulence intensity on the time-averaged streamline pattern around the circular cylinder. As seen in Figure 5, when the turbulence intensity increases the length of recirculation region decreases. For instance, while the normalized length of recirculation region after the cylinder, $L_{s} / D$ is measured as 1.225 at turbulence intensity of $T u=0.8 \%$, it reduces to the value of $L_{s} / D=1.0822$ at turbulence intensity of $T u=7 \%$. The dimensionless wake length attenuates to the value of $L_{s} / D=0.8542$ when turbulence intensity increases from $T u=7 \%$ to $12 \%$. Furthermore, the location of saddle point, $S$ moves in upstream direction toward the rear stagnation point of the cylinder by increasing turbulence intensity. For example, while the saddle point, $S$ takes place at location of $X / D=1.725$ at turbulence intensity, $T u=0.8 \%$ it occurs at dimensionless distances, $X / D=1.56$ and 1.365 at $T u=7 \%$ and $12 \%$ respectively. Additionally, the extent of focal points, $F_{1}$ and $F_{2}$ gets smaller by increasing turbulence intensity. As inferred from Figure 5, the distance between focal points, $F_{1}$ and $F_{2}$ is not remarkably affected by the increase in turbulence intensity. Actually, this distance is correlated with the drag coefficient on the cylinder surface. Drag coefficient attenuates when the distance between 
focal points get smaller. The formation of small circulation bubbles, $B_{1}$ and $B_{2}$ takes place on the cylinder surface as seen in Figure 1 . The extent of these bubbles, $B_{1}$ and $B_{2}$ reduces by increasing turbulence intensity. Furthermore, the formation of these bubbles, $B_{1}$ and $B_{2}$ moves towards the rear stagnation point of the cylinder by increasing turbulence intensity.

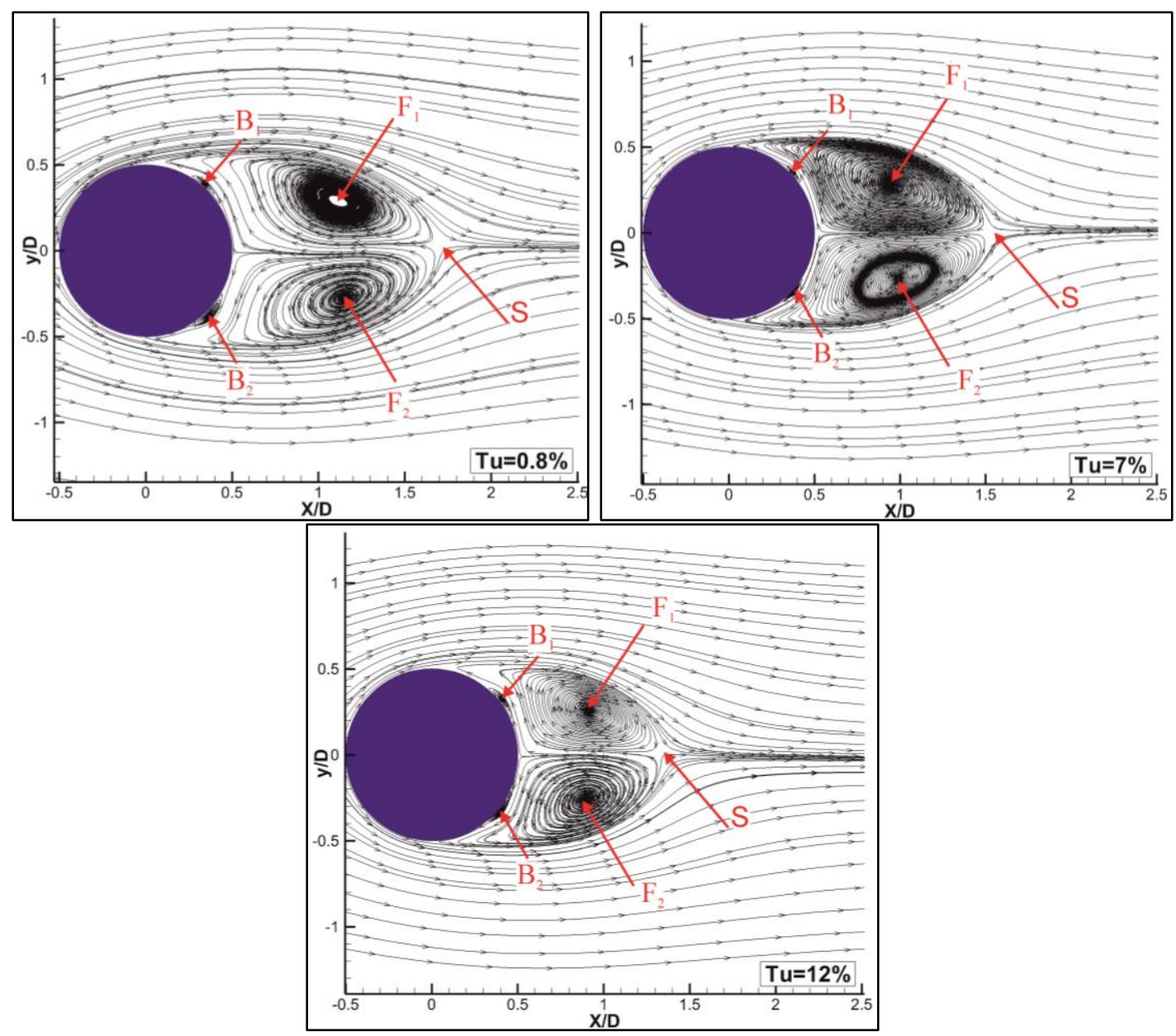

Figure 5. The effect of turbulence intensity on the time-averaged streamline pattern around the cylinder

Figure 6 shows the effect of turbulence intensity on the time-averaged streamwise velocity distribution around the cylinder. The timeaveraged streamwise velocity, $u$ is normalized with the free-stream velocity, $U$. As observed from the Figure 6, the extent of wake region in horizontal direction behind the cylinder gets smaller by increasing turbulence intensity which can also revealed from the streamline pattern in Figure 5. But the size of this region remains unchanged in vertical direction. The increasing turbulence intensity caused the absolute magnitude of peak negative and positive velocities to be higher. Furthermore, the size of maximum peak negative velocity clusters grows up when turbulence intensity increased from $T u=0.8 \%$ to $12 \%$. The increased turbulence intensity induced narrower wake region and higher absolute magnitudes of positive and negative velocities can be attributed to the higher momentum of fluid flow at higher turbulence intensities. 
As inferred from Table 1, the drag coefficient, $C_{D}$ gets higher when turbulence intensity increases from $T u=0.8 \%$ to $7 \%$ and $12 \%$. For instance, the drag coefficient, $C_{D}$ increases from 1.039 to 1.128 as turbulence intensity goes up from $T u=0.8 \%$ to $12 \%$. But this increase is not much since the drag coefficient grows by $8 \%$ while turbulence intensity increases by 15 times. The drag increase can be attributed to the turbulence intensity induced increase in friction and pressure over the surface of the cylinder as concluded from mean pressure and shear stress distribution on the cylinder surface. When the turbulence intensity increases, the more fluid molecules hit the cylinder surface and thus the friction between cylinder surface and fluid molecules increases causing higher drag coefficients, $C_{D}$. The increase in the drag coefficient with turbulence intensity was also reported in the investigation of Norberg [21]. In this study, the drag coefficient, $C_{D}$ was found to increase from 0.98 to 1.03 when turbulence intensity alters from $0.1 \%$ to $1.4 \%$ at Reynolds number, $R e=3 \times 10^{3}$. Furthermore, as noticed, the value of drag coefficient, $C_{D}$ in the study of Norberg [21] at turbulence intensity of $T u=1.4 \%$ is nearly same with the current study at $T u=0.8 \%$.

Table 2 demonstrates the impact of the turbulence intensity on the root mean square (RMS) of lift coefficient, $C_{L}$ of the cylinder. As seen in Table 2, RMS of lift coefficient gets higher by increasing turbulence intensity. For example, RMS of lift coefficient increases from 0.236 to 0.417 when the turbulence intensity grows from $T u=0.8 \%$ to $12 \%$. The reason of the increase in the RMS of lift coefficient, $C_{L}$ with turbulence intensity is the enhancement of momentum transfer. The increasing turbulence intensity augments the momentum of fluid molecules in all flow regions around the cylinder.

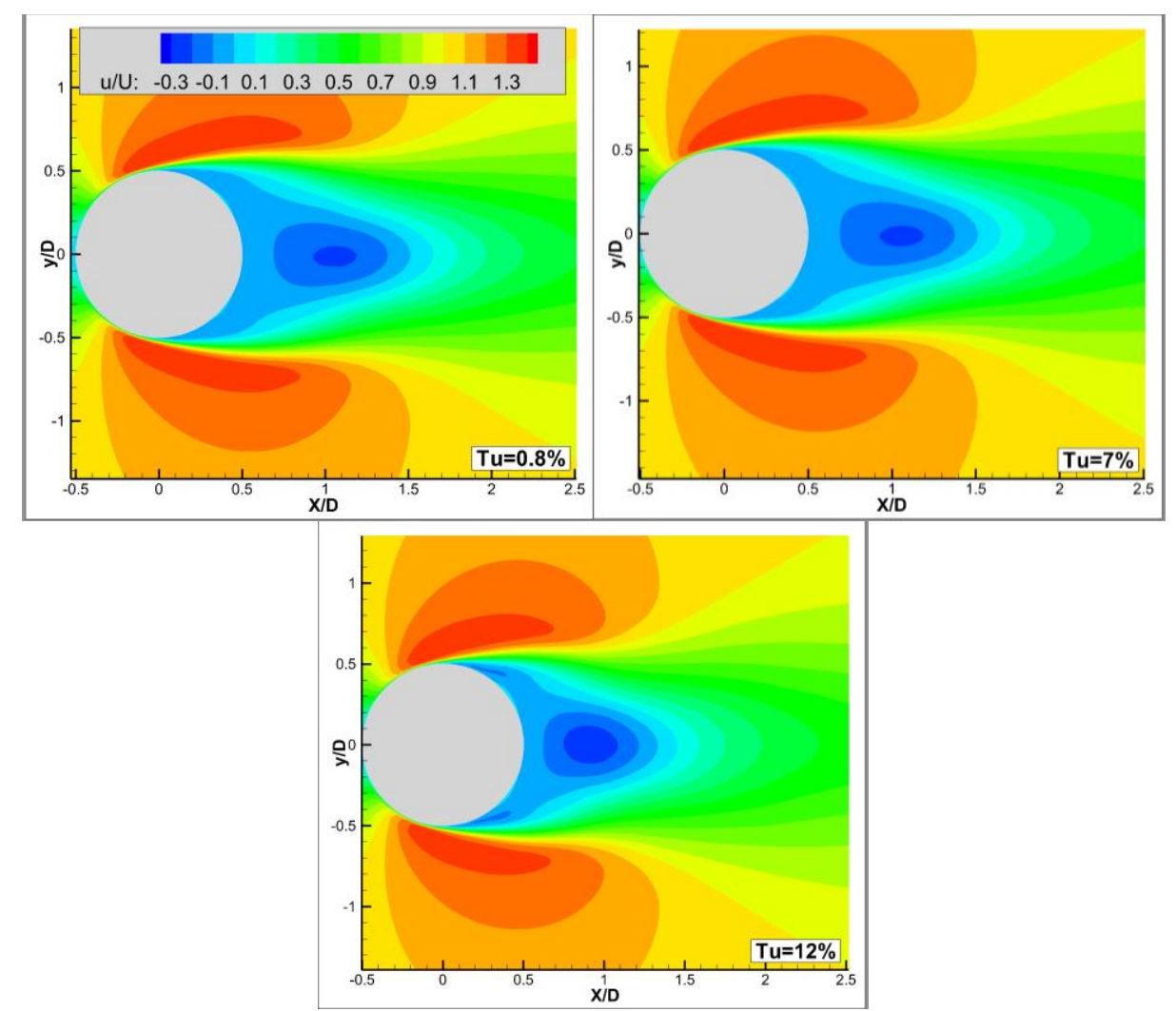

Figure 6. The effect of turbulence intensity on the normalized time-averaged streamwise velocity, $u / U$ distributions around the cylinder 
Table 1. The influence of turbulence intensity on the drag coefficient, $C_{D}$ of the cylinder

\begin{tabular}{|c|c|}
\hline Turbulence intensity (\%) & Drag coefficient, $C_{D}$ \\
\hline 0.8 & 1.039 \\
\hline 7 & 1.070 \\
\hline 12 & 1.128 \\
\hline
\end{tabular}

Table 2. The turbulence intensity effect on the root mean square (RMS) of lift coefficient, $C_{L}$ of the cylinder

\begin{tabular}{|c|c|}
\hline $\begin{array}{c}\text { Turbulence intensity } \\
(\%)\end{array}$ & $\begin{array}{c}\text { RMS of lift coefficient, } \\
C_{L}\end{array}$ \\
\hline 0.8 & 0.236 \\
\hline 7 & 0.310 \\
\hline 12 & 0.417 \\
\hline
\end{tabular}

Figure 7 demonstrates the turbulence intensity effect on the mean pressure coefficient, $C_{p}$ distribution around the circular cylinder at Reynolds number, $R e=5 \times 10^{3}$. Due to the quite symmetrical pressure distribution around the cylinder just a half of the circumferential distribution $\left(0^{\circ} \leq \theta \leq 180^{\circ}\right)$ is demonstrated. Figure 7 shows that the increasing turbulence intensity have an effect on the decreasing peak negative pressure coefficient. For instance, while the peak negative pressure coefficient was observed as -1.22, at turbulence intensity, $T u=0.8 \%$, it was observed as -1.30 and -1.36 when the turbulence intensity was increased to $T u=7 \%$ and $12 \%$ respectively. The increase in the peak negative magnitude of pressure coefficient, $C_{p}$ denotes the pressure induced drag increase which will be discussed in following sections. In the region of $0^{\circ} \leq \theta \leq 60^{\circ}$, the mean pressure coefficient distribution is almost identical for three turbulence intensity value. So, in this region, the mean pressure coefficient is independent from turbulence intensity for this Reynolds number, $R e=5 \times 10^{3}$. But for the region of $60^{\circ} \leq \theta \leq 120^{\circ}$, the distribution of mean pressure coefficient considerably alters by the increase in turbulence intensity. Because in this region, the laminar separation starts at different location on cylinder surface at different turbulence intensities. As seen in Figure 7, the location of peak negative pressure coefficient moves in downstream direction by increasing turbulence intensity. For instance, at turbulence intensity of $T u=0.8$, the peak negative magnitude of pressure coefficient is $C_{p}=-1.222$ occurs at location on cylinder surface $\theta=70.22^{\circ}$. On the other hand, at turbulence intensity, $T u=7$ the peak magnitude pressure coefficient $C_{p}=-1.30$ takes place at position on cylinder surface of $\theta=72.02^{\circ}$. In Figure 7 , the point where the $C_{p}$ distribution over the cylinder surface becomes straights denotes the separation location on the cylinder surface. As observed, the point where $C_{p}$ distribution becomes straights moves towards the rear stagnation point by increasing turbulence intensity. In other words, laminar separation over the cylinder surface delayed by increasing turbulence intensity which will be discussed in the Figure 8. The distribution of mean pressure coefficient, $C_{p}$ is consistent with the studies of [2124].

The turbulence intensity effect on the mean shear stress, $\tau_{\text {mean }}$ distribution over the cylinder surface at Reynolds number, $R e=5 \times 10^{3}$ is demonstrated in Figure 8. The shear stress distribution on the cylinder surface is correlated to the friction coefficient distribution, $C_{f}$ with a relation of $C_{f}=2 \tau_{w} / \rho U^{2}$. As observed from Figure 8 , the shear stress over the cylinder surface augments with increasing turbulence intensities. The increasing shear stress distribution with turbulence intensity causes higher friction forces on the cylinder surface. Thus, the friction induced drag coefficient gets higher by increasing turbulence intensity which will be discussed in the following sections. In this figure, the points where the mean shear stress, $\tau_{\text {mean }}$ thus friction coefficient, $C_{f}$ is equal to zero denotes the laminar separation location on the cylinder surface. As interpreted from the Figure, the point where the mean shear stress, $\tau_{\text {mean }}$ is zero moves toward the rear stagnation point of the cylinder, in other words laminar separation on cylinder surface is delayed by increasing turbulence intensity. The increased mixing by increased turbulence intensity makes the boundary layer to resist a higher adverse pressure gradient and thus the separation is postponed by increasing turbulence intensity. 


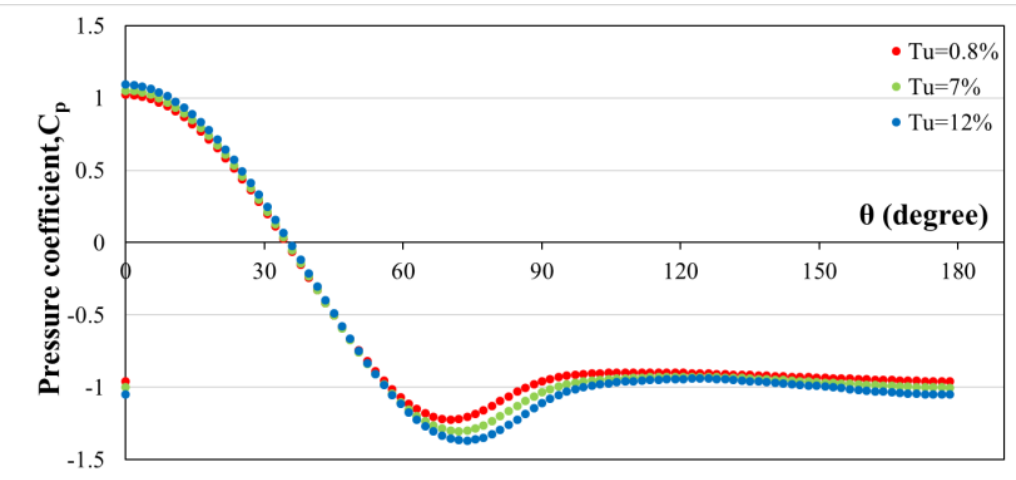

Figure 7. The effect of turbulence intensity on the mean pressure coefficient, $C_{p}$ distribution on the cylinder surface

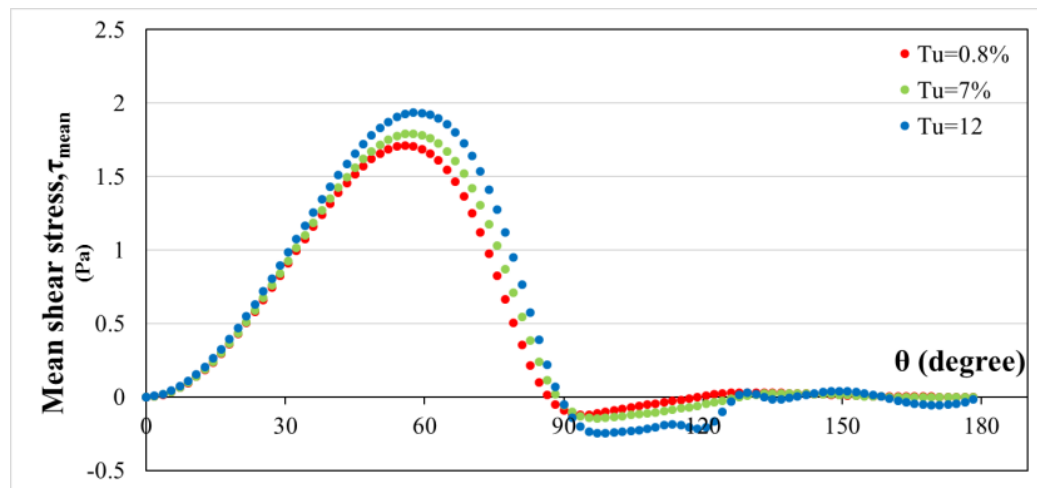

Figure 8. The turbulence intensity effect on the mean shear stress, $\tau_{\text {mean }}$ distribution over the cylinder surface

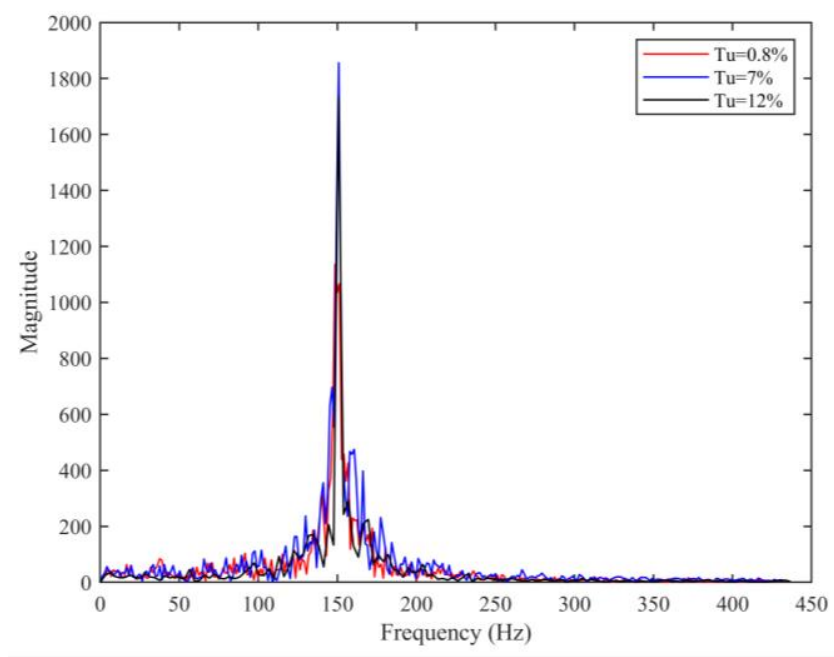

Figure 9. The turbulence intensity effect on the vortex shedding frequency on the cylinder 
In fluid dynamics, adverse pressure gradient happens as the static pressure gets higher in the flow direction. Figure 9 demonstrates the effect of turbulence intensity on the vortex shedding frequency or Strouhal number on the circular cylinder. As seen in Figure 9, the increasing turbulence intensity does not have an effect on the dominant peak vortex shedding frequency, $f$. Because the dominant peak vortex shedding frequency, $f$ is equal to the $150 \mathrm{~Hz}$ for three examined turbulence intensity case, $\mathrm{Tu}=0.8 \%, 7 \%$ and $12 \%$ with corresponding Strouhal number of $S t=0.205$ based on the Equation 3. In this equation, dominant peak vortex frequency, $f$ is the $150 \mathrm{~Hz}$, the cylinder diameter, $D$ is the 0.01 meter and freestream velocity, $U$ is the $7.30 \mathrm{~m} / \mathrm{s}$ thus the Strouhal number, St equals to 0.205 . The calculated Strouhal number is very consistent to the ones computed in the study of Norberg [21]. He was observed the Strouhal number as $S t=0.213$ and 0.209 at turbulence intensities of $T u=0.1 \%$ and $1.4 \%$, respectively at Reynolds number, $R e=3 \times 10^{3}$. Furthermore, Ahn et al. [15] stated that the magnitude of the Strouhal number is independent of the value of the turbulence intensity and it only slightly changes with Reynolds number which is consistent with the current study.

\section{CONCLUSIONS}

In this study, the impact of the turbulence intensity on the flow structure of the circular cylinder was numerically investigated at sub-critical Reynolds number of $R e=5 \times 10^{3}$ and turbulence intensities of $T u=0.8 \%, 7 \%$ and $12 \%$. The unsteady flow structure was analyzed with $\mathrm{k}-\omega$ based DES turbulence model in Ansys Fluent package program. According to this study, the position of saddle point, $S$ approaches to the rear stagnation point of the cylinder in upstream direction by increasing turbulence intensity. For instance, whereas the saddle point, $S$ occurs at the dimensionless location of $X / D=1.725$ at turbulence intensity, $T u=0.8 \%$ it happens at dimensionless locations, $X / D=1.56$ and 1.365 at $T u=7 \%$ and $12 \%$ respectively. The increasing turbulence intensity have an effect on the decreasing peak negative pressure coefficient. For example, whereas the peak negative pressure coefficient was detected as
-1.22 , at turbulence intensity, $T u=0.8 \%$, it was detected as -1.30 and -1.36 when the turbulence intensity was raised to $T u=7 \%$ and $12 \%$ respectively. The increase in the peak negative magnitude of pressure coefficient, $C_{p}$ denotes the increase in pressure induced drag. Furthermore, the position of peak negative pressure coefficient approaches to the rear stagnation point of the cylinder by increasing turbulence intensity. The increasing turbulence intensity caused the absolute magnitude of peak negative and positive velocities to be higher. The location in which the mean shear stress, $\tau_{\text {mean }}$ is zero moves toward the rear stagnation point of the cylinder, in other words laminar separation on cylinder surface is delayed by increasing turbulence intensity. The increased mixing by increased turbulence intensity makes the boundary layer to resist a higher adverse pressure gradient and thus the separation is postponed by increasing turbulence intensity. Finally, the drag coefficient, $C_{D}$ increases as turbulence intensity gets higher from $T u=0.8 \%$ to $7 \%$ and $12 \%$; namely, it has been concluded that the drag coefficient, $C_{D}$ has raised from 1.039 to 1.128 as turbulence intensity augments from $T u=0.8 \%$ to $12 \%$.

\section{REFERENCES}

1. Pinar, E., Ozkan, G. M., Durhasan, T., Aksoy, M.M., Akilli, H., Sahin, B., 2015. Flow Structure Around Perforated Cylinders in Shallow Water. Journal of Fluids and Structures, 55, 52-63.

2. Ozgoren, M., Pinar, E., Sahin, B., Akilli, H., 2011. Comparison of Flow Structures in the Downstream Region of a Cylinder and Sphere. International Journal of Heat and Fluid Flow, 32(6), 1138-1146.

3. Rashidi, S., Hayatdavoodi, M., Esfahani, J.A., 2016. Vortex Shedding Suppression and Wake Control: A Review. Ocean Engineering, 126, 57-80.

4. Najafi, L., Firat, E., Akilli, H., 2016. Timeaveraged Near-wake of a Yawed Cylinder. Ocean Engineering, 113, 335-349

5. Mannini, C., 2015. Applicability of URANS and DES Simulations of Flow Past Rectangular 
Cylinders and Bridge Sections. Computation, 3(3), 479-508.

6. You, J.Y., Kwon, O.J., 2010. Numerical Comparisons Between URANS and Hybrid RANS/LES at a High Reynolds Number Flow Using Unstructured Meshes. International Journal of Aeronautical and Space Sciences, 11(1), 41-48.

7. Uzun, A., Yousuff Hussaini, M., 2012. An Application of Delayed Detached Eddy Simulation to Tandem Cylinder Flow Field Prediction. Computers and Fluids, 60, 71-85.

8. Travin, A., Shur, M., Strelets, M., Spalart P., 1999. Detached-Eddy Simulations Past a Circular Cylinder. Flow, Turbulence and Combustion, 63, 293-313.

9. Zhao, W., Wan, D., Sun R., 2016. DetachedEddy Simulation of Flows Over a Circular Cylinder at High Reynolds Number. TwentySixth International Ocean and Polar Engineering Conference.

10.Zhao, R., Yan, C., 2012. Detailed Investigation of DETACHED-EDDY Simulation for the Flow Past a Circular Cylinder at $\mathrm{Re}=3900$. Applied Mechanics and Materials, 232, 471-476.

11. Karasu, I., 2019. Silindir Etrafindaki Kararsız Akışın Farklı Türbülans Modelleri ile Sayısal Olarak İncelenmesi. Bilecik Şeyh Edebali Üniversitesi, Fen Bilimleri Dergisi, 6(1), 77-84.

12. Norberg, C., Sunden, B., 1987. Turbulence and Reynolds Number Effects on the Flow and Fluid Forces on a Single Cylinder in Cross Flow. Journal of Fluids and Structures, 1(3), 337-357.

13. Bloor, M.S., 1964. The Transition to Turbulence in the Wake of a Circular Cylinder. Journal of Fluid Mechanics, 19(02), 290.

14. Gerrard, J.H., 1965. A Disturbance-sensitive Reynolds Number Range of the Flow Past a Circular Cylinder. Journal of Fluid Mechanics, 22(01), 187.

15. Ahn, J., Sparrow, E., Gorman, J., 2017. Turbulence Intensity Effects on Heat Transfer and Fluid-flow for a Circular Cylinder in Crossflow. International Journal of Heat and Mass Transfer, 113, 613-621.
16. Smith, M.C., 1966. Effects of Turbulence on Laminar Skin Friction and Heat Transfer. Physics of Fluids, 9(12), 2337.

17. Sundén, B., 1979. A Theoretical Investigation of the Effect of Freestream Turbulence on Skin Friction and Heat Transfer for a Bluff Body. International Journal of Heat and Mass Transfer, 22(7), 1125-1135.

18. Sidebottom, W., Ooi, A., Jones, D., 2015. A Parametric Study of Turbulent Flow Past a Circular Cylinder Using Large Eddy Simulation. Journal of Fluids Engineering, 137(9), 091202.

19. Durhasan, T., Pinar, E., Ozkan, G. M., Akilli, H., Sahin, B., 2019. The Effect of Shroud on Vortex Shedding Mechanism of Cylinder. Applied Ocean Research, 84, 51-61.

20. Menter, F.R., Kuntz, M., Langtry, R., 2003. Ten Years of Industrial Experience with the SST Turbulence Model. Turbulence, Heat and Mass Transfer, 4(1), 625-632.

21. Norberg, C., 1987. Effects of Reynolds Number and a Low-intensity Freestream Turbulence on the Flow Around a Circular Cylinder, Chalmers University, Goteborg, Sweden, Technological Publications, 1-55.

22. Moussaed, C., Wornom, S., Salvetti, M.V., Koobus, B., Dervieux, A., 2014. Impact of Dynamic Subgrid-scale Modeling in Variational Multiscale Large-eddy Simulation of Bluff-body Flows. Acta Mechanica, 225(12), 3309-3323.

23. Pang, A.L., Skote, M., Lim, S.Y., 2016. Modelling High Re Flow Around a 2d Cylindrical Bluff Body Using the k- $\omega$ (sst) Turbulence Model. Progress in Computational Fluid Dynamics, An International Journal, 16(1), 48.

24. Wang, H.F., Zhou, Y., Mi, J., 2012. Effects of Aspect Ratio on the Drag of a Wall-mounted Finite-length Cylinder in Subcritical and Critical Regimes. Experiments in Fluids. 